\title{
Effect of sugammadex versus glycopyrrolate- neostigmine mixture on catheter-related bladder discomfort after retrograde intrarenal surgery: A retrospective observational analysis
}

Gi-Ho Koh

Chosun University Hospital

Jun-Young Park

Asan Medical Center

Jihion Yu

Asan Medical Center

Jin-Young Seo

Chosun University Hospital

Sang-A Lee

Asan Medical Center

YoonJu Go

Kyung Hee University School of Medicine

Jai-Hyun Hwang

Asan Medical Center

Hyungseok Seo

Kyung Hee University Hospital at Gangdong

Young-Kug Kim ( $\nabla$ kyk@amc.seoul.kr)

Asan Medical Center, University of Ulsan College of Medicine https://orcid.org/0000-0002-1982-3053

Research article

Keywords: catheter-related bladder discomfort, sugammadex, glycopyrrolate-neostigmine mixture, retrograde intrarenal surgery

Posted Date: January 21 st, 2020

DOI: https://doi.org/10.21203/rs.2.21459/v1

License: (1) This work is licensed under a Creative Commons Attribution 4.0 International License. Read Full License 


\section{Abstract}

Background: Catheter-related bladder discomfort (CRBD) is one of the most common postoperative symptoms. Although sugammadex and glycopyrrolate-neostigmine mixture are both used for the reversal of neuromuscular blockade, their effects on CRBD have not been compared side-to-side. We investigated the effect of the neuromuscular blockade reversal agents on CRBD after urologic surgery.

Methods: We retrospectively reviewed the medical records of 136 patients who underwent retrograde intrarenal surgery between July 2018 and January 2019. Patients were divided into the S group (sugammadex; $\mathrm{n}=65$ ) and the $\mathrm{G}$ group (glycopyrrolate-neostigmine mixture; $\mathrm{n}=71$ ). Primary outcome was moderate-to-severe CRBD at $0 \mathrm{~h}$ postoperatively. We also evaluated moderate-to-severe CRBD at 1, 2, and $6 \mathrm{~h}$ postoperatively, duration of postanesthetic care unit (PACU) stay, postoperative pain, postoperative analgesic requirement, and drug-related side effects.

Results: The incidence of moderate-to-severe CRBD at $0 \mathrm{~h}$ postoperatively was significantly lower in the $\mathrm{G}$ group than in the $S$ group ( $39.4 \%$ vs. $69.2 \%, p=0.001)$. The two groups did not show significant differences in the incidences of moderate-to-severe CRBD at 1,2, and $6 \mathrm{~h}$ postoperatively, postoperative pain, and postoperative analgesic requirement. The duration of PACU stay was significantly shorter in the G group (46.0 min vs. 53.0 min, $p=0.047$ ). Except for dry mouth, drug-related side effects did not show significant differences between the two groups.

Conclusion: Compared with sugammadex, glycopyrrolate-neostigmine mixture was associated with a lower incidence of CRBD immediately after urologic surgery and shorter PACU stay.

\section{Introduction}

Retrograde intrarenal surgery (RIRS) is considered a first-line treatment option for the removal of intrarenal stones [1]. Urinary catheterization is generally performed at the end of RIRS to facilitate urination and assess hematuria in patients undergoing this surgery [2]. Catheter-related bladder discomfort (CRBD) is characterized by elevated symptoms of urinary frequency and urgency as well as suprapubic area discomfort caused by the urinary catheter [3-5]. Moderate-to-severe CRBD can be extremely distressing to the patient and may cause reduced quality of postoperative care at the postanesthetic care unit (PACU) and necessitate additional therapy for CRBD $[6,7]$.

The glycopyrrolate-neostigmine mixture is commonly used for reversal of nondepolarizing neuromuscular blockade at the end of surgery under general anesthesia. Glycopyrrolate-an adjuvant of neostigmine-has an antimuscarinic effect and has been reported to be effective in preventing CRBD [8]. However, traditional reversal agents, such as the glycopyrrolate-neostigmine mixture, have significant limitations, including indirect mechanisms of reversal of neuromuscular blockade and limited and unpredictable efficacy [9].

Sugammadex-a modified gamma-cyclodextrin that encapsulates and inactivates unbound aminosteroid neuromuscular blocking drugs-has been reported to be superior to traditional reversal agents $[9,10]$. Because of clinical benefits, including fast and predictable reversal of any degree of block, increased patient safety, and reduced incidence of residual block on recovery, sugammadex is emerging as a more favorable option over 
traditional reversal agents of neuromuscular blockade [9, 11-13]. However, to the best of our knowledge, the effect of sugammadex on CRBD has not yet been investigated.

This study was designed to compare the effect of sugammadex versus glycopyrrolate-neostigmine mixture on CRBD in patients undergoing RIRS. We hypothesized that compared to sugammadex, glycopyrrolateneostigmine mixture could significantly reduce the incidence of moderate-to-severe CRBD.

\section{Materials And Methods}

\section{Study Design and Population}

This study was approved by the Institutional Review Board of Asan Medical Center (No. 2019 - 0257). This retrospective study included 20- to 90-year-old patients with American Society of Anesthesiologists (ASA) physical status class I-III who underwent elective RIRS for renal stones under general anesthesia between July 2018 and January 2019. If the patient received repeated RIRS during the study period, data from only the first RIRS were included in this study. The preoperative, intraoperative, and postoperative data were collected from a retrospective review of the Asan Medical Center Information System Electronic Medical Records. Patients with incomplete data, preoperative urinary catheter insertion, and failed surgery for stone removal were excluded. The requirement for written informed consent was waived by the Institutional Review Board owing to the retrospective study design. This study was carried out in accordance with the STROBE (Strengthening the Reporting of Observational Studies in Epidemiology) checklist [14].

\section{Anesthetic and Surgical Techniques}

General anesthesia was performed according to the standardized clinical protocol of our institution. No premedication was administered before anesthesia. Noninvasive blood pressure or invasive intraarterial blood pressure, pulse oximetry, three-lead electrocardiography, esophageal temperature, capnography, train-of-four (TOF) stimulation, and the bispectral index (BIS) were applied to all patients. TOF monitoring was carried out at the adductor pollicis muscle in response to ulnar nerve stimulation. General anesthesia was induced using propofol $(2 \mathrm{mg} / \mathrm{kg})$ and rocuronium bromide $(0.6 \mathrm{mg} / \mathrm{kg})$. After the patient was unconscious, endotracheal intubation was performed when the twitch in response to TOF stimulation was absent. Anesthesia was maintained using sevoflurane in a $50 \%$ oxygen-nitrous oxide mixture. The end-tidal concentration of sevoflurane was adjusted to maintain a target BIS value of $40-60$ and a systolic blood pressure within $\pm 20 \%$ of the baseline level. The esophageal temperature was maintained at $36^{\circ} \mathrm{C}-37^{\circ} \mathrm{C}$ via forced air-warming. Corresponding to the TOF count, either sugammadex ( $2 \mathrm{mg} / \mathrm{kg}$; S group) or glycopyrrolate (8 $\mu \mathrm{g} / \mathrm{kg}$ ) with neostigmine ( $40 \mu \mathrm{g} / \mathrm{kg}$; G group) was administered to reverse the neuromuscular blockade at the end of surgery. If the TOF count was 2 or 3 , sugammadex was administered, and if the TOF count was $\geq 4$ at the end of surgery, the glycopyrrolate-neostigmine mixture was administered. Extubation was performed after the patient responded to all commands (BIS $\geq 90$ ) and recovered from neuromuscular blockade (TOF ratio $\geq$ 90\%). All patients were transferred to the PACU after recovering consciousness.

In the PACU, when the patient complained of moderate-to-severe CRBD, tramadol (50 mg) was administered as rescue therapy. When postoperative pain was $\geq 4$ on a numeric rating scale (NRS) without CRBD symptoms, such as urgency or suprapubic discomfort, fentanyl $(50 \mu \mathrm{g})$ was administered as rescue therapy. For patients 
complaining of both moderate-to-severe CRBD and postoperative pain (NRS $\geq 4$ ), we assessed the main chief complaint and treated the patients using either tramadol or fentanyl. All patients were reassessed the CRBD severity and/or postoperative pain every $10 \mathrm{~min}$ until the symptoms subsided after rescue therapy at the PACU. Patients were discharged from the PACU if the postanesthetic recovery score was $\geq 8$, NRS was $<4$, CRBD was absent or mild, and symptoms of nausea/vomiting were tolerable [15]. After PACU discharge, ketorolac $(30 \mathrm{mg}$ ) was administered to treat moderate-to-severe CRBD or postoperative pain (NRS $\geq 4$ ) in the general ward. If patients had contraindications to nonsteroidal anti-inflammatory drugs (NSAIDs) or if the severity of CRBD and postoperative pain was not reduced, tramadol (50 mg) or pethidine (25 mg) was administered.

RIRS was performed with the patient in the lithotomy position on an endourological table and under C-arm fluoroscopy control. A safety hydrophilic guide wire was placed into the renal pelvis via semirigid or flexible ureteroscopy. Retrograde pyelography via fluoroscopy with a contrast dye was performed to examine the size and location of the stone. After the distal end of the scope was placed in the renal pelvis, a holmium laser and nitinol basket were used for stone fragmentation and retrieval. A double-J stent was routinely placed in all patients at the end of surgery. After the completion of surgery, a 14-Fr urinary catheter was inserted after lubricating it with $2 \%$ lidocaine gel, and the balloon was inflated using $5 \mathrm{~mL}$ of distilled water. The urinary catheter was fixed in the suprapubic area by using adhesive tape.

\section{Measurement and Definitions of Variables}

Preoperative variables, such as age, sex, body mass index, smoking, ASA physical status, comorbidities (hypertension, diabetes mellitus, chronic obstructive pulmonary disease, coronary artery disease, cerebrovascular disease, chronic kidney disease, and benign prostate hyperplasia), and urine culture results, were extracted from the electronic medical records. Smoking was defined as the use of cigarettes at least once in the 8 weeks before surgery. Hypertension was defined as a systolic arterial blood pressure $>140 \mathrm{~mm}$ $\mathrm{Hg}$ and diastolic arterial blood pressure $>90 \mathrm{~mm} \mathrm{Hg}$, and/or the use of antihypertensive drugs. Diabetes mellitus was defined as a history of type 1 or type 2 diabetes mellitus treated using either oral hypoglycemic drugs or insulin. Chronic obstructive pulmonary disease was defined as a self-reported history of diagnosis and/or use of medication. Coronary artery disease was defined as a history of angina, myocardial infarction, percutaneous coronary intervention, or coronary artery bypass graft surgery. Cerebrovascular disease was defined as a history of stroke, cerebral hemorrhage, or carotid artery stent or angioplasty. Chronic kidney disease was defined as a history of diagnosis, regardless of medical treatment. Benign prostate hyperplasia was defined as a self-reported history of diagnosis and/or use of medication. A positive preoperative urine culture was defined as $\geq 100,000$ colony-forming unit/mL of a pathogenic organism within 30 days before surgery.

Intraoperative variables, such as duration of anesthesia, duration of surgery, stone characteristics (largest size, number, location, type, and composition), and time to extubation, were also collected. Largest stone size was evaluated using the maximum length of the largest stone viewed via kidney-ureter-bladder radiography or nonenhanced computerized tomography. Stone number was categorized as single or multiple. Stone location was categorized as pelvis, upper calyx, middle calyx, lower calyx, and multiple locations. Stone type was categorized as staghorn or nonstaghorn. Stone composition was categorized into calcium oxalate 
monohydrate, uric acid, mixed, and others (carbonate apatite, cystine, and protein). Time to extubation was defined as the time from the administration of the reversal agent to tracheal extubation.

\section{Primary and Secondary Outcomes}

The primary outcome was the incidence of moderate-to-severe CRBD at $0 \mathrm{~h}$ postoperatively (on admission to the PACU). The secondary outcomes were the incidences of moderate-to-severe CRBD at 1, 2, and $6 \mathrm{~h}$ postoperatively and the duration of PACU stay. Other outcomes included postoperative pain at $0,1,2$, and $6 \mathrm{~h}$, analgesic requirement during $24 \mathrm{~h}$ postoperatively, and postoperative drug-related side effects within $6 \mathrm{~h}$.

According to previous reports, the evaluation of postoperative CRBD is one of the important factors for the management of patients after urologic surgery $[5,7,16,17]$. Therefore, at our institution, the severity of CRBD in patients who underwent urologic surgery was routinely assessed at $0,1,2$, and 6 h postoperatively by anesthesiologists or registered nurses at the PACU and general ward. Postoperative CRBD was recorded as follows: none, did not complain of any CRBD even upon asking; mild, revealed only upon questioning; moderate, reported without questioning but was not accompanied by any behavioral response; and severe, stated on their own and followed by behavioral responses, such as a strong verbal response, flailing limbs, and even attempting to pull out the urinary catheter $[5,7,16,17]$.

The duration of PACU stay was defined as the duration from admission to discharge from the PACU. Postoperative pain was defined as a sharp or dull pain in the flank area and was assessed using a NRS ( $0=$ no pain to 10 = worst imaginable pain). Doses of all opioids and NSAIDs administered to patients during the $24 \mathrm{~h}$ postoperatively were converted to intravenous morphine equianalgesic doses according to published conversion factors (intravenous morphine $10 \mathrm{mg}=$ tramadol $100 \mathrm{mg}=$ fentanyl $100 \mu \mathrm{g}=$ ketorolac $30 \mathrm{mg}=$ pethidine $100 \mathrm{mg}$ ) [18, 19]. Postoperative drug-related side effects (nausea/vomiting, dry mouth, dizziness, headache, shivering, and fever) were also assessed.

\section{Statistical Analysis}

Continuous data were estimated as mean \pm standard deviation for normally distributed data or as median (interquartile range) for nonnormally distributed data. Categorical variables were expressed as number (percentage) or odds ratio (OR) and $95 \%$ confidence interval $(95 \% \mathrm{Cl})$. Normal distribution of data was assessed using the Kolmogorov-Smirnov test. Differences between groups were assessed using Fisher's exact test or the $\chi^{2}$ test for categorical variables and using Student's t-test for continuous data, such as body mass index, with normal distribution. For nonnormally distributed data, such as age, duration of anesthesia, duration of surgery, largest stone size, time to extubation, duration of PACU stay, and analgesic requirement, the Mann-Whitney U test was used.

The primary outcome, i.e., the incidence of moderate-to-severe CRBD at $0 \mathrm{~h}$ postoperatively (on admission to the PACU), was compared using the $\chi^{2}$ test. Incidences of CRBD or moderate-to-severe CRBD between the two groups at 1, 2, and 6 h postoperatively were compared using the $\chi^{2}$ test or Fisher's exact test, as appropriate. Postoperative NRS scores of both the groups at each time were compared using a two-way repeatedmeasures analysis of variance. A p value $<0.05$ was considered significant. Data were analyzed using MedCalc version 19.1 (MedCalc Software, Ostend, Belgium), and IBM SPSS Statistics for Windows, Version 24.0 (IBM Corp., Armonk, NY, USA). 
Previous studies reported that the incidences of moderate-to-severe CRBD at $0 \mathrm{~h}$ postoperatively varied among patients who underwent urologic surgery and received glycopyrrolate as an adjuvant of neostigmine for the reversal of neuromuscular blockade $[5,7,8,16,17,20]$. However, the incidences of moderate-to-severe CRBD at $0 \mathrm{~h}$ postoperatively were not reported in patients who underwent urologic surgery and received sugammadex. To calculate the sample size for this study, the incidence of moderate-to-severe CRBD in patients who received the glycopyrrolate-neostigmine mixture was considered as $41 \%$-the average incidence obtained from previous studies $[5,7,8,16,17,20]$. Moreover, we considered a difference of $30 \%$ in the incidence of moderate-to-severe CRBD (i.e., $41 \%$ vs. $71 \%$ ) between the glycopyrrolate-neostigmine mixture and sugammadex. Therefore, we assumed that at least 61 patients would be necessary in each group to have a power of $90 \%$.

\section{Results}

Of the 198 patients who underwent RIRS for renal stones during the study period, 62 were excluded because of incomplete data $(n=59)$, preoperative urinary catheter insertion $(n=2)$, and failed stone removal $(n=1)$. Therefore, 136 patients were analyzed. The $S$ group comprised 65 (47.8\%) patients and the $\mathrm{G}$ group comprised 71 (52.2\%) patients (Fig. 1). The preoperative and intraoperative characteristics of the two groups are shown in Tables 1 and 2 . The preoperative and intraoperative characteristics, except the time to extubation, were not significantly different between the two groups. 
Table 1

Preoperative characteristics

\begin{tabular}{|c|c|c|c|}
\hline & $S$ group $(n=65)$ & $G$ group $(n=71)$ & p-value \\
\hline Age, yrs & $61.0(56.0-70.0)$ & $60.0(48.0-66.0)$ & 0.221 \\
\hline $\begin{array}{l}\text { Sex } \\
\text { Male } \\
\text { Female }\end{array}$ & $\begin{array}{l}45(69.2) \\
20(30.8)\end{array}$ & $\begin{array}{l}43(60.6) \\
28(39.4)\end{array}$ & 0.291 \\
\hline Body mass index, $\mathrm{kg} / \mathrm{m}^{2}$ & $25.1 \pm 2.9$ & $24.6 \pm 2.7$ & 0.262 \\
\hline Smoking & $13(20.0)$ & $18(25.4)$ & 0.457 \\
\hline $\begin{array}{l}\text { ASA physical status } \\
\text { Class I } \\
\text { Class II } \\
\text { Class III }\end{array}$ & $\begin{array}{l}15(23.1) \\
45(69.2) \\
5(7.7)\end{array}$ & $\begin{array}{l}18(25.4) \\
48(67.6) \\
5(7.0)\end{array}$ & 0.949 \\
\hline Hypertension & $32(49.2)$ & $30(42.3)$ & 0.414 \\
\hline Diabetes mellitus & $22(33.8)$ & $18(25.4)$ & 0.278 \\
\hline Chronic obstructive pulmonary disease & $1(1.5)$ & $1(1.4)$ & $>0.999$ \\
\hline Coronary artery disease & $2(3.1)$ & $2(2.8)$ & $>0.999$ \\
\hline Cerebrovascular disease & $1(1.5)$ & $1(1.4)$ & $>0.999$ \\
\hline Chronic kidney disease & $4(6.2)$ & $5(7.0)$ & $>0.999$ \\
\hline Benign prostate hyperplasia & $5(7.7)$ & $2(2.8)$ & 0.258 \\
\hline Positive urine culture & $5(7.7)$ & $5(7.0)$ & $>0.999$ \\
\hline \multicolumn{4}{|c|}{$\begin{array}{l}\text { Data are expressed as mean } \pm \text { standard deviation, median (interquartile range), or number (\%). } S \text { group } \\
\text { comprised patients who received sugammadex for reversal of neuromuscular blockade. } G \text { group } \\
\text { comprised patients who received glycopyrrolate-neostigmine mixture for reversal of neuromuscular } \\
\text { blockade. ASA, American Society of Anesthesiologists. }\end{array}$} \\
\hline
\end{tabular}


Table 2

Intraoperative characteristics

\begin{tabular}{|c|c|c|c|}
\hline & $S$ group $(n=65)$ & G group $(n=71)$ & p-value \\
\hline Duration of anesthesia, min & $90.0(70.0-110.0)$ & $90.0(70.0-110.0)$ & 0.734 \\
\hline Duration of surgery, min & $60.0(46.0-84.0)$ & $62.0(42.0-77.5)$ & 0.450 \\
\hline Largest stone size, $\mathrm{mm}$ & $15.0(10.0-20.0)$ & $15.0(10.0-20.0)$ & 0.812 \\
\hline $\begin{array}{l}\text { Stone number } \\
\text { Single } \\
\text { Multiple }\end{array}$ & $\begin{array}{l}18(27.7) \\
47(72.3)\end{array}$ & $\begin{array}{l}24(33.8) \\
47(66.2)\end{array}$ & 0.441 \\
\hline $\begin{array}{l}\text { Stone location } \\
\text { Pelvis } \\
\text { Upper calyx } \\
\text { Middle calyx } \\
\text { Lower calyx } \\
\text { Multiple }\end{array}$ & $\begin{array}{l}12(18.5) \\
2(3.1) \\
0 \\
10(15.4) \\
41(63.1)\end{array}$ & $\begin{array}{l}11(15.5) \\
4(5.6) \\
2(2.8) \\
15(21.1) \\
39(54.9)\end{array}$ & 0.563 \\
\hline $\begin{array}{l}\text { Stone type } \\
\text { Staghorn } \\
\text { Nonstaghorn }\end{array}$ & $\begin{array}{l}6(9.2) \\
59(90.8)\end{array}$ & $\begin{array}{l}12(16.9) \\
59(83.1)\end{array}$ & 0.187 \\
\hline $\begin{array}{l}\text { Stone composition } \\
\text { Calcium oxalate monohydrate } \\
\text { Uric acid } \\
\text { Mixed } \\
\text { Others * }\end{array}$ & $\begin{array}{l}15(23.1) \\
17(26.2) \\
31(47.7) \\
2(3.0)\end{array}$ & $\begin{array}{l}17(23.9) \\
11(15.5) \\
37(52.1) \\
6(8.4)\end{array}$ & 0.481 \\
\hline Time to extubation, $\min$ & $5.0(3.0-6.0)$ & $6.0(4.0-9.0)$ & 0.008 \\
\hline \multicolumn{4}{|c|}{$\begin{array}{l}\text { Data are expressed as median (interquartile range) or number (\%). The } S \text { group comprises patients who } \\
\text { received sugammadex for the reversal of neuromuscular blockade. The } \mathrm{G} \text { group comprises patients who } \\
\text { received the glycopyrrolate- neostigmine mixture for the reversal of neuromuscular blockade. *Others } \\
\text { included carbonate apatite, cysteine, and protein. }\end{array}$} \\
\hline
\end{tabular}

The incidence of moderate-to-severe CRBD at $0 \mathrm{~h}$ postoperatively was significantly lower in the $\mathrm{G}$ group than in the S group (39.4\% vs. $69.2 \%$, OR: $0.289,95 \%$ Cl: $0.142-0.589, p=0.001)$ (Fig. 2). The incidences of moderate-to-severe CRBD at 1, 2, and $6 \mathrm{~h}$ postoperatively did not differ significantly between the $S$ group and G group ( 1 h: $24.6 \%$ vs. $12.7 \%, p=0.073 ; 2$ h: $3.1 \%$ vs. $1.4 \%, p=0.606 ; 6$ h: $1.5 \%$ vs. $0.0 \%, p=0.478$ ) (Fig. 2 ). The incidences of CRBD at 0 and $1 \mathrm{~h}$ postoperatively were significantly lower in the $\mathrm{G}$ group than in the $\mathrm{S}$ group (Table 3). At 2 and $6 \mathrm{~h}$ postoperatively, the incidences of CRBD were not significantly different between the two groups (Table 3). 
Table 3

Incidence and severity of CRBD in patients who underwent retrograde intrarenal surgery

\begin{tabular}{|c|c|c|c|c|c|c|c|c|}
\hline & \multicolumn{8}{|c|}{ Postoperative time, $\mathrm{h}$} \\
\hline & \multicolumn{2}{|l|}{0} & \multicolumn{2}{|l|}{1} & \multicolumn{2}{|l|}{2} & \multicolumn{2}{|l|}{6} \\
\hline Group & $\begin{array}{l}\text { S } \\
\text { group }\end{array}$ & $\begin{array}{l}\text { G } \\
\text { group }\end{array}$ & $\begin{array}{l}\text { S } \\
\text { group }\end{array}$ & $\begin{array}{l}\text { G } \\
\text { group }\end{array}$ & $\begin{array}{l}\text { S } \\
\text { group }\end{array}$ & $\begin{array}{l}\text { G } \\
\text { group }\end{array}$ & $\begin{array}{l}\text { S } \\
\text { group }\end{array}$ & $\begin{array}{l}\text { G } \\
\text { group }\end{array}$ \\
\hline $\begin{array}{l}\text { Incidence } \\
\text { of CRBD }\end{array}$ & $\begin{array}{l}58 \\
(89.2)\end{array}$ & $\begin{array}{l}54 \\
(76.1)^{\star}\end{array}$ & $\begin{array}{l}64 \\
(98.5)\end{array}$ & $\begin{array}{l}63 \\
(88.7)^{\star}\end{array}$ & $\begin{array}{l}55 \\
(84.6)\end{array}$ & $\begin{array}{l}58 \\
(81.7)\end{array}$ & $\begin{array}{l}48 \\
(73.8)\end{array}$ & $\begin{array}{l}44 \\
(62.0)\end{array}$ \\
\hline $\begin{array}{l}\text { Severity } \\
\text { of CRBD } \\
\text { Mild } \\
\text { Moderate } \\
\text { Severe }\end{array}$ & $\begin{array}{l}13 \\
(20.0) \\
36 \\
(55.4) \\
9 \\
(13.8)\end{array}$ & $\begin{array}{l}26 \\
(36.6)^{\star} \\
20 \\
(28.2)^{\star} \\
8 \\
(11.3)\end{array}$ & $\begin{array}{l}48 \\
(73.8) \\
16 \\
(24.6) \\
0 \\
(0.0)\end{array}$ & $\begin{array}{l}54 \\
(76.1) \\
9 \\
(12.7) \\
0(0.0)\end{array}$ & $\begin{array}{l}53 \\
(81.5) \\
2 \\
(3.1) \\
0 \\
(0.0)\end{array}$ & $\begin{array}{l}57 \\
(80.3) \\
1 \\
(1.4) \\
0 \\
(0.0)\end{array}$ & $\begin{array}{l}47 \\
(72.3) \\
1 \\
(1.5) \\
0 \\
(0.0)\end{array}$ & $\begin{array}{l}44 \\
(62.0) \\
0 \\
(0.0) \\
0 \\
(0.0)\end{array}$ \\
\hline \multicolumn{9}{|c|}{$\begin{array}{l}\text { Data are expressed as number (\%). The } S \text { group comprises patients who received sugammadex for the } \\
\text { reversal of neuromuscular blockade. The } G \text { group comprises patients who received the glycopyrrolate- } \\
\text { neostigmine mixture for the reversal of neuromuscular blockade. CRBD, catheter-related bladder } \\
\text { discomfort; } 0 \text { h postoperatively, on admission to the postanesthetic care unit. Data are compared using the } \\
\chi 2 \text { test or Fisher's exact test. }{ }^{\star} p<0.05 \text { versus the } G \text { group. }\end{array}$} \\
\hline
\end{tabular}

Our study had a statistical power of $94.5 \%$ for detecting a difference in the incidence of moderate-to-severe $\mathrm{CRBD}$ at $\mathrm{O} \mathrm{h}$ postoperatively between the glycopyrrolate-neostigmine mixture and sugammadex. Therefore, our study is considered to have sufficient statistical power.

The median duration of PACU stay was significantly shorter in the G group than in the S group (46.0 min [40.0-62.0] vs. $53.0 \mathrm{~min}[41.0-70.0], p=0.047$ ) (Fig. 3).

Postoperative pain at $0,1,2$, and $6 \mathrm{~h}$ was not significantly different between the two groups (Table 4). Tramadol requirement at $0 \mathrm{~h}$ postoperatively was significantly lower in the $\mathrm{G}$ group than in the $\mathrm{S}$ group ( $0.0 \mathrm{mg}$ [0.0-50.0] vs. $50.0 \mathrm{mg}$ [0.0-50.0], $\mathrm{p}=0.003$ ). Analgesic requirement during $24 \mathrm{~h}$ postoperatively was not significantly different between the two groups (15.0 mg [10.0-20.0] vs. $15.0 \mathrm{mg}$ [5.0-20.0], $\mathrm{p}=0.642)$. The incidence of dry mouth was significantly higher in the $G$ group than in the $S$ group $(12.7 \%$ vs. $1.5 \%, p=0.018)$. However, the incidences of nausea/vomiting, dizziness, headache, shivering, and fever within $6 \mathrm{~h}$ postoperatively were comparable between the two groups (Table 5) 
Table 4

Comparison of postoperative pain in patients who underwent retrograde intrarenal surgery

\begin{tabular}{|c|c|c|c|}
\hline & \multicolumn{3}{|c|}{ Numeric rating scale } \\
\hline & $S$ group $(n=65)$ & $G$ group $(n=71)$ & p-value \\
\hline \multicolumn{3}{|l|}{ Postoperative time, hrs } & 0.814 \\
\hline 0 & $0.0(0.0-0.0)$ & $0.0(0.0-2.0)$ & \\
\hline 1 & $0.0(0.0-2.0)$ & $0.0(0.0-2.0)$ & \\
\hline 2 & $0.0(0.0-2.0)$ & $0.0(0.0-2.0)$ & \\
\hline 6 & $0.0(0.0-0.0)$ & $0.0(0.0-1.0)$ & \\
\hline \multicolumn{4}{|c|}{$\begin{array}{l}\text { Data are expressed as median (interquartile range). The } S \text { group comprises patients who received } \\
\text { sugammadex for the reversal of neuromuscular blockade. The } \mathrm{G} \text { group comprises patients who receivec } \\
\text { the glycopyrrolate-neostigmine mixture for the reversal of neuromuscular blockade. } 0 \mathrm{~h} \text { postoperatively } \\
\text { on admission to the postanesthetic care unit. Data are compared using a two-way repeated-measures } \\
\text { analysis of variance. }\end{array}$} \\
\hline
\end{tabular}

Table 5

Drug-related side effects in patients underwent retrograde intrarenal surgery

\begin{tabular}{|llll|}
\hline & S group $(\mathbf{n}=65)$ & G group $(\mathbf{n}=71)$ & p-value \\
\hline Nausea/vomiting & $3(4.6)$ & $3(4.2)$ & $>0.999$ \\
\hline Dry mouth & $1(1.5)$ & $9(12.7)$ & 0.018 \\
\hline Dizziness & $0(0.0)$ & $1(1.4)$ & $>0.999$ \\
\hline Headache & $0(0.0)$ & $1(1.4)$ & $>0.999$ \\
\hline Shivering & $0(0.0)$ & $1(1.4)$ & 0.999 \\
\hline Fever & $1(1.5)$ & $4(5.6)$ & 0.368 \\
\hline $\begin{array}{l}\text { Data are expressed as number }(\%) \text {. The S group comprises patients who received sugammadex for the } \\
\text { reversal of neuromuscular blockade. The G group comprises patients who received the glycopyrrolate- } \\
\text { neostigmine mixture for the reversal of neuromuscular blockade. Data are compared using Fisher's exact } \\
\text { test. }\end{array}$ & \\
\hline
\end{tabular}

\section{Discussion}

In the present study, we evaluated the effect of sugammadex versus glycopyrrolate-neostigmine mixture on postoperative CRBD in patients who underwent RIRS. We found that the incidence of moderate-to-severe CRBD after RIRS was significantly lower with the glycopyrrolate-neostigmine mixture administration than with sugammadex administration. However, the beneficial effect of glycopyrrolate-neostigmine mixture on moderate-to-severe CRBD was limited to only $0 \mathrm{~h}$ postoperatively after RIRS. Nevertheless, the duration of 
PACU stay was significantly shorter with the glycopyrrolate-neostigmine mixture administration than with sugammadex administration.

RIRS is a safe and effective procedure that has gained worldwide popularity owing to its minimal invasiveness in the management of renal stones [1]. RIRS is associated with lower blood loss, postoperative pain, complication rate, and hospital stay duration than is percutaneous nephrolithotomy, and provides higher stone-free rate than does extracorporeal shock wave lithotripsy [21, 22]. Moreover, RIRS is being considered the standard therapy for renal stones $<2 \mathrm{~cm}$ and can be used as a valid treatment for renal stones $>2 \mathrm{~cm}$ in patients with severe comorbidities [21, 23].

Stimulation of muscarinic receptors on the urinary bladder, which is induced by acetylcholine released from activated cholinergic nerves, results in the voluntary and involuntary contractions of the detrusor muscle [24]. The symptoms of CRBD are due to involuntary contractions of the bladder owing to irritation by the urinary catheter, and are mediated by the activation of muscarinic receptors, especially receptor types 2 and $3[5,16$, 25-27]. CRBD is a symptom frequently complained about during the postoperative period by patients with a urinary catheter. However, postoperative CRBD tends to be considered an unimportant concern among physicians. Importantly, CRBD is a known risk factor of emergence agitation in the PACU, and 47-90\% of patients complain of CRBD during the postoperative period [28]. In particular, moderate-to-severe CRBD, which may need urgent management, occurs in 50-67\% of patients at the PACU after undergoing urologic surgery [3, 4]. Moreover, the incidence of postoperative complications, such as surgical wound dehiscence, postoperative bleeding, or increased severity of coronary artery disease, may increase because of the symptoms of CRBD, which may consequently prolong hospital stay [27]. Therefore, active management, including the use of drugs for preventing CRBD, is needed in clinical practice.

We found that the incidence of moderate-to-severe CRBD was lower with the glycopyrrolate-neostigmine mixture administration than with sugammadex administration. Muscarinic antagonists are able to inhibit detrusor overactivity; therefore, previous studies have reported that various agents with antimuscarinic properties, such as glycopyrrolate, butylscopolamine, solifenacin, ketamine, tramadol, and dexmedetomidine, are effective in the prevention and treatment of $\operatorname{CRBD}[7,8,16,24,27,29-32]$. Unlike glycopyrrolate, sugammadex has no effect on anticholinesterases [33]. This could explain the result of our study wherein the incidence of moderate-to-severe CRBD was higher with sugammadex administration than with the glycopyrrolate-neostigmine mixture administration.

Our study also showed that the incidence of moderate-to-severe CRBD with the glycopyrrolate-neostigmine mixture administration was 39.4\%, which was lower than that reported by Agarwal et al. (100\% and 63\%) [16, 17]. This difference in incidence may be explained in part by the sex ratio and anesthetic agent used. Male sex is a known risk factor for moderate-to-severe CRBD [34]. In addition, the incidence of CRBD was lower with sevoflurane than with propofol as a maintenance agent of general anesthesia [20]. The proportion of male patients in our study was lower than that in previous studies $(60.6 \%$ vs. $96 \%$ and $87 \%)[16,17]$. Furthermore, in our study, sevoflurane was used to maintain anesthesia, whereas propofol was infused in previous studies $[16,17]$. 
We also found that the effect of the glycopyrrolate-neostigmine mixture on moderate-to-severe CRBD was limited to only $0 \mathrm{~h}$ postoperatively. The elimination half time of glycopyrrolate is $0.8 \pm 0.3 \mathrm{~h}$;[35] this may explain why the incidence of moderate-to-severe CRBD significantly differs between the two groups at only $0 \mathrm{~h}$ postoperatively.

Compared to traditional reversal agents, sugammadex has a different mechanism of action to reverse neuromuscular blockade [36]. While traditional reversal agents act by increasing acetylcholine, sugammadex forms a complex with rocuronium, thereby removing the neuromuscular blocking agents from the neuromuscular junction [36]. Therefore, sugammadex has less cholinergic and anticholinergic effects, unlike traditional reversal agents [33]. Furthermore, because of its different mechanism of action, sugammadex is associated with less respiratory and cardiovascular adverse events than are traditional reversal agents [36]. Thus, sugammadex is being reported to be superior to traditional reversal agents for the reversal of neuromuscular blockade $[9,12,36]$. Nevertheless, sugammadex was ineffective in CRBD in this study. In addition, the high cost of sugammadex restricts its widespread use as an alternative to the glycopyrrolateneostigmine mixture [37,38]. Therefore, reversal agents for neuromuscular blockade should be carefully determined considering their effect on postoperative CRBD, especially in patients with risk factors of CRBD $[27,34]$.

In the present study, we found that the duration of PACU stay was shorter with the glycopyrrolate-neostigmine mixture administration than with sugammadex administration. The reduced PACU stay with the glycopyrrolate-neostigmine mixture administration, rather than with sugammadex administration, is at least partly related to the lower incidence of moderate-to-severe CRBD at $0 \mathrm{~h}$ postoperatively. A previous study reported that the reduction of CRBD severity results in decreased duration of PACU stay in patients who underwent transurethral resection of the prostate [39]. Furthermore, Geldner et al. argued that the duration of PACU stay could be affected by other factors, such as postoperative pain, even if sugammadex administration reduced the time to extubation [40]. Therefore, administering the glycopyrrolate-neostigmine mixture may be advantageous in preventing moderate-to-severe CRBD, which results in delayed PACU discharge.

Our study has several limitations. First, this study was retrospective. However, as anesthesia and surgery were performed using our institution's standardized protocol, we consider that the biases affecting the results of the study were minimized. Second, the severity of CRBD was not assessed and recorded by one investigator. Nevertheless, the grade of CRBD was evaluated according to the standard criteria of CRBD grade by a clinically experienced anesthesiologist or registered nurses who were well-informed about CRBD. Despite these limitations, the strength of our study is that to our knowledge, it is the first one to investigate the effect of sugammadex versus glycopyrrolate-neostigmine mixture on CRBD.

\section{Conclusions}

This study demonstrated that the glycopyrrolate-neostigmine mixture administration, rather than sugammadex administration, reduced the incidence of moderate-to-severe CRBD at $0 \mathrm{~h}$ postoperatively in patients who underwent RIRS, thereby reducing the duration of PACU stay. Our result suggests that the glycopyrrolate-neostigmine mixture has an advantage over sugammadex as a reversal agent of neuromuscular blockade with respect to CRBD, which causes delayed PACU discharge. Therefore, our findings

Page $12 / 20$ 
provide valuable information about the effect of reversal agents for neuromuscular blockade on CRBD in patients undergoing RIRS.

\section{Abbreviations}

ASA

American Society of Anesthesiologists; BIS:bispectral index; Cl:confidence interval; CRBD:catheter-related bladder discomfort; NRS:numeric rating scale; NSAIDs nonsteroidal anti-inflammatory drugs; OR:odds ratio; PACU:postanesthetic care unit; RIRS:retrograde intrarenal surgery; STROBE:Strengthening the Reporting of Observational Studies in Epidemiology; TOF:train of four.

\section{Declarations}

\section{Ethics approval and consent to participate}

This study was approved by the Institutional Review Board of Asan Medical Center (No. 2019-0257). The requirement for written informed consent was waived by the Institutional Review Board owing to the retrospective study design.

\section{Consent for publication}

Not applicable

\section{Availability of data and materials}

The datasets used and/or analyzed during the current study are available from the corresponding author on reasonable request.

\section{Competing interests}

The authors declare that they have no competing interests.

\section{Funding}

The authors have no sources of funding to declare for this manuscript.

\section{Authors' contributions}


conceptualization, G.-H.K., H.S. and Y.-K.K.; methodology, G.-H.K., J.-H.H, H.S. and Y.-K.K.; validation, G.-H.K., J.Y.P., J.Y., H.S. and Y.-K.K.; formal analysis, G.-H.K., H.S. and Y.-K.K.; investigation, G.-H.K., J.-Y.P., J.Y. and S.-A.L.; resources, J.-Y.P. and Y.-K.K.; data curation, G.-H.K. and S.-A.L.; writing-original draft preparation, G.-H.K. and J.-Y.S.; writing-review and editing, Y.G., H.S. and Y.-K.K.; visualization, G.-H.K., H.S. and Y.-K.K.; supervision, J.H.H. and Y.-K.K; project administration, G.-H.K. and Y.-K.K. All authors read and approved the final manuscript.

\section{Acknowledgements}

Not applicable

\section{References}

1.

Sanguedolce F, Bozzini G, Chew B, Kallidonis P, de la Rosette J. The Evolving Role of Retrograde Intrarenal Surgery in the Treatment of Urolithiasis. Eur Urol Focus. 2017;3(1):46-55.

2.

Gokce MI, Tokatli Z, Suer E, Hajiyev P, Akinci A, Esen B. Comparison of shock wave lithotripsy (SWL) and retrograde intrarenal surgery (RIRS) for treatment of stone disease in horseshoe kidney patients. Int Braz $\mathrm{J}$ Urol. 2016;42(1):96-100.

3.

Kim DH, Park JY, Yu J, Lee SA, Park S, Hwang JH, Koh GH, Kim YK. Intravenous Lidocaine for the Prevention of Postoperative Catheter-Related Bladder Discomfort in Male Patients Undergoing Transurethral Resection of Bladder Tumors: A Randomized, Double-Blind, Controlled Trial. Anesthesia and analgesia 2019.

4.

Park JY, Hong JH, Yu J, Kim DH, Koh GH, Lee SA, Hwang JH, Kong YG, Kim YK. Effect of Ketorolac on the Prevention of Postoperative Catheter-Related Bladder Discomfort in Patients Undergoing Robot-Assisted Laparoscopic Radical Prostatectomy: A Randomized, Double-Blinded, Placebo-Controlled Study. J Clin Med $2019,8(6)$.

5.

Agarwal A, Raza M, Singhal V, Dhiraaj S, Kapoor R, Srivastava A, Gupta D, Singh PK, Pandey CK, Singh U. The efficacy of tolterodine for prevention of catheter-related bladder discomfort: a prospective, randomized, placebo-controlled, double-blind study. Anesthesia analgesia. 2005;101(4):1065-7. table of contents. 6.

Tauzin-Fin P, Sesay M, Svartz L, Krol-Houdek MC, Maurette P. Sublingual oxybutynin reduces postoperative pain related to indwelling bladder catheter after radical retropubic prostatectomy. $\mathrm{Br} \mathrm{J}$ Anaesth. 2007;99(4):572-5. 
7.

Agarwal A, Yadav G, Gupta D, Singh PK, Singh U. Evaluation of intra-operative tramadol for prevention of catheter-related bladder discomfort: a prospective, randomized, double-blind study. Br J Anaesth. 2008;101(4):506-10.

8.

Kim HC, Lim SM, Seo H, Park HP. Effect of glycopyrrolate versus atropine coadministered with neostigmine for reversal of rocuronium on postoperative catheter-related bladder discomfort in patients undergoing transurethral resection of bladder tumor: a prospective randomized study. J Anesth. 2015;29(6):831-5.

9.

Hristovska AM, Duch P, Allingstrup M, Afshari A. Efficacy and safety of sugammadex versus neostigmine in reversing neuromuscular blockade in adults. Cochrane Database Syst Rev. 2017;8:CD012763.

10.

Schaller SJ, Fink H. Sugammadex as a reversal agent for neuromuscular block: an evidence-based review. Core Evid. 2013;8:57-67.

11.

Khuenl-Brady KS, Wattwil M, Vanacker BF, Lora-Tamayo Jl, Rietbergen H, Alvarez-Gomez JA. Sugammadex provides faster reversal of vecuronium-induced neuromuscular blockade compared with neostigmine: a multicenter, randomized, controlled trial. Anesthesia analgesia. 2010;110(1):64-73.

12.

Abad-Gurumeta A, Ripolles-Melchor J, Casans-Frances R, Espinosa A, Martinez-Hurtado E, Fernandez-Perez C, Ramirez JM, Lopez-Timoneda F, Calvo-Vecino JM. Evidence Anaesthesia Review G: A systematic review of sugammadex vs neostigmine for reversal of neuromuscular blockade. Anaesthesia. 2015;70(12):1441-52. 13.

Carron M, Baratto F, Zarantonello F, Ori C. Sugammadex for reversal of neuromuscular blockade: a retrospective analysis of clinical outcomes and cost-effectiveness in a single center. Clinicoecon Outcomes Res. 2016;8:43-52.

14.

von Elm E, Altman DG, Egger M, Pocock SJ, Gøtzsche PC, Vandenbroucke JP. The Strengthening the Reporting of Observational Studies in Epidemiology (STROBE) statement: guidelines for reporting observational studies. The Lancet. 2007;370(9596):1453-7.

15.

Aldrete JA, Kroulik D. A postanesthetic recovery score. Anesthesia analgesia. 1970;49(6):924-34.

16.

Agarwal A, Gupta D, Kumar M, Dhiraaj S, Tandon M, Singh PK. Ketamine for treatment of catheter related bladder discomfort: a prospective, randomized, placebo controlled and double blind study. Br J Anaesth. 2006;96(5):587-9.

17.

Agarwal A, Dhiraaj S, Pawar S, Kapoor R, Gupta D, Singh PK. An evaluation of the efficacy of gabapentin for prevention of catheter-related bladder discomfort: a prospective, randomized, placebo-controlled, double-blind study. Anesthesia analgesia. 2007;105(5):1454-7. table of contents.

18.

Page $15 / 20$ 
Cepeda MS, Carr DB, Miranda N, Diaz A, Silva C, Morales O. Comparison of morphine, ketorolac, and their combination for postoperative pain: results from a large, randomized, double-blind trial. Anesthesiology. 2005;103(6):1225-32.

19.

McPherson MLM. Demystifying opioid conversion calculations: a guide for effective dosing. Maryland: American Society of Health-System Pharmacists;: Bethesda; 2009.

20.

Kim HC, Park HP, Lee J, Jeong MH, Lee KH. Sevoflurane vs. propofol in post-operative catheter-related bladder discomfort: a prospective randomized study. Acta Anaesthesiol Scand. 2017;61(7):773-80.

21.

De S, Autorino R, Kim FJ, Zargar H, Laydner H, Balsamo R, Torricelli FC, Di Palma C, Molina WR, Monga M, et al. Percutaneous nephrolithotomy versus retrograde intrarenal surgery: a systematic review and metaanalysis. European urology. 2015;67(1):125-37.

22.

Junbo L, Yugen L, Guo J, Jing H, Ruichao Y, Tao W. Retrograde Intrarenal Surgery vs. Percutaneous Nephrolithotomy vs. Extracorporeal Shock Wave Lithotripsy for Lower Pole Renal Stones 10-20 mm: A Metaanalysis and Systematic Review. Urology journal. 2019;16(2):97-106.

23.

Zheng C, Xiong B, Wang H, Luo J, Zhang C, Wei W, Wang Y. Retrograde intrarenal surgery versus percutaneous nephrolithotomy for treatment of renal stones > 2 cm: a meta-analysis. Urol Int. 2014;93(4):417-24.

24.

Andersson KE, Yoshida M. Antimuscarinics and the overactive detrusor-which is the main mechanism of action? European urology. 2003;43(1):1-5.

25.

Chess-Williams R. Muscarinic receptors of the urinary bladder: detrusor, urothelial and prejunctional. Auton Autacoid Pharmacol. 2002;22(3):133-45.

26.

Eglen RM. Muscarinic receptor subtypes in neuronal and non-neuronal cholinergic function. Auton Autacoid Pharmacol. 2006;26(3):219-33.

27.

Bai Y, Wang X, Li X, Pu C, Yuan H, Tang Y, Li J, Wei Q, Han P. Management of Catheter-Related Bladder Discomfort in Patients Who Underwent Elective Surgery. J Endourol. 2015;29(6):640-9.

28.

Lepouse C, Lautner CA, Liu L, Gomis P, Leon A. Emergence delirium in adults in the post-anaesthesia care unit. Br J Anaesth. 2006;96(6):747-53.

29.

Ryu JH, Hwang JW, Lee JW, Seo JH, Park HP, Oh AY, Jeon YT, Do SH. Efficacy of butylscopolamine for the treatment of catheter-related bladder discomfort: a prospective, randomized, placebo-controlled, double-blind study. Br J Anaesth. 2013;111(6):932-7.

30.

Nam K, Seo JH, Ryu JH, Oh AY, Lee T, Park HP, Jeon YT, Hwang JW. Randomized, clinical trial on the preventive effects of butylscopolamine on early postoperative catheter-related bladder discomfort. Surgery. 
2015;157(2):396-401.

31.

Chung JM, Ha HK, Kim DH, Joo J, Kim S, Sohn DW, Kim SH, Seo HK. Evaluation of the Efficacy of Solifenacin for Preventing Catheter-Related Bladder Discomfort After Transurethral Resection of Bladder Tumors in Patients With Non-Muscle Invasive Bladder Cancer: A Prospective, Randomized, Multicenter Study. Clin Genitourin Cancer. 2017;15(1):157-62.

32.

Shariat Moharari R, Lajevardi M, Khajavi M, Najafi A, Shariat Moharari G, Etezadi F. Effects of intra-operative ketamine administration on postoperative catheter-related bladder discomfort: a double-blind clinical trial. Pain Pract. 2014;14(2):146-50.

33.

Naguib M. Sugammadex: another milestone in clinical neuromuscular pharmacology. Anesthesia analgesia. 2007;104(3):575-81.

34.

Binhas M, Motamed C, Hawajri N, Yiou R, Marty J. Predictors of catheter-related bladder discomfort in the post-anaesthesia care unit. Ann Fr Anesth Reanim. 2011;30(2):122-5.

35.

Ali-Melkkila T, Kanto J, lisalo E. Pharmacokinetics and related pharmacodynamics of anticholinergic drugs. Acta Anaesthesiol Scand. 1993;37(7):633-42.

36.

Carron M, Zarantonello F, Tellaroli P, Ori C. Efficacy and safety of sugammadex compared to neostigmine for reversal of neuromuscular blockade: a meta-analysis of randomized controlled trials. J Clin Anesth. 2016;35:1-12.

37.

Zealley K, Taylor A, Raju P, Rodney G. Is appropriately conducted neostigmine reversal inferior to sugammadex? Anaesthesia 2018, 73(9):1166-1167.

38.

Ledowski T, Hillyard S, Kozman A, Johnston F, Gillies E, Greenaway M, Kyle BC. Unrestricted access to sugammadex: impact on neuromuscular blocking agent choice, reversal practice and associated healthcare costs. Anaesthesia intensive care. 2012;40(2):340-3.

39.

Sabetian G, Zand F, Asadpour E, Ghorbani M, Adibi P, Hosseini MM, Zeyghami S, Masihi F. Evaluation of hyoscine N-butyl bromide efficacy on the prevention of catheter-related bladder discomfort after transurethral resection of prostate: a randomized, double-blind control trial. Int Urol Nephrol. 2017;49(11):1907-13. 40.

Geldner G, Niskanen M, Laurila P, Mizikov V, Hübler M, Beck G, Rietbergen H, Nicolayenko E. A randomised controlled trial comparing sugammadex and neostigmine at different depths of neuromuscular blockade in patients undergoing laparoscopic surgery*. Anaesthesia. 2012;67(9):991-8.

\section{Figures}


Patients who underwent retrograde intrarenal surgery

$$
(\mathrm{n}=198)
$$

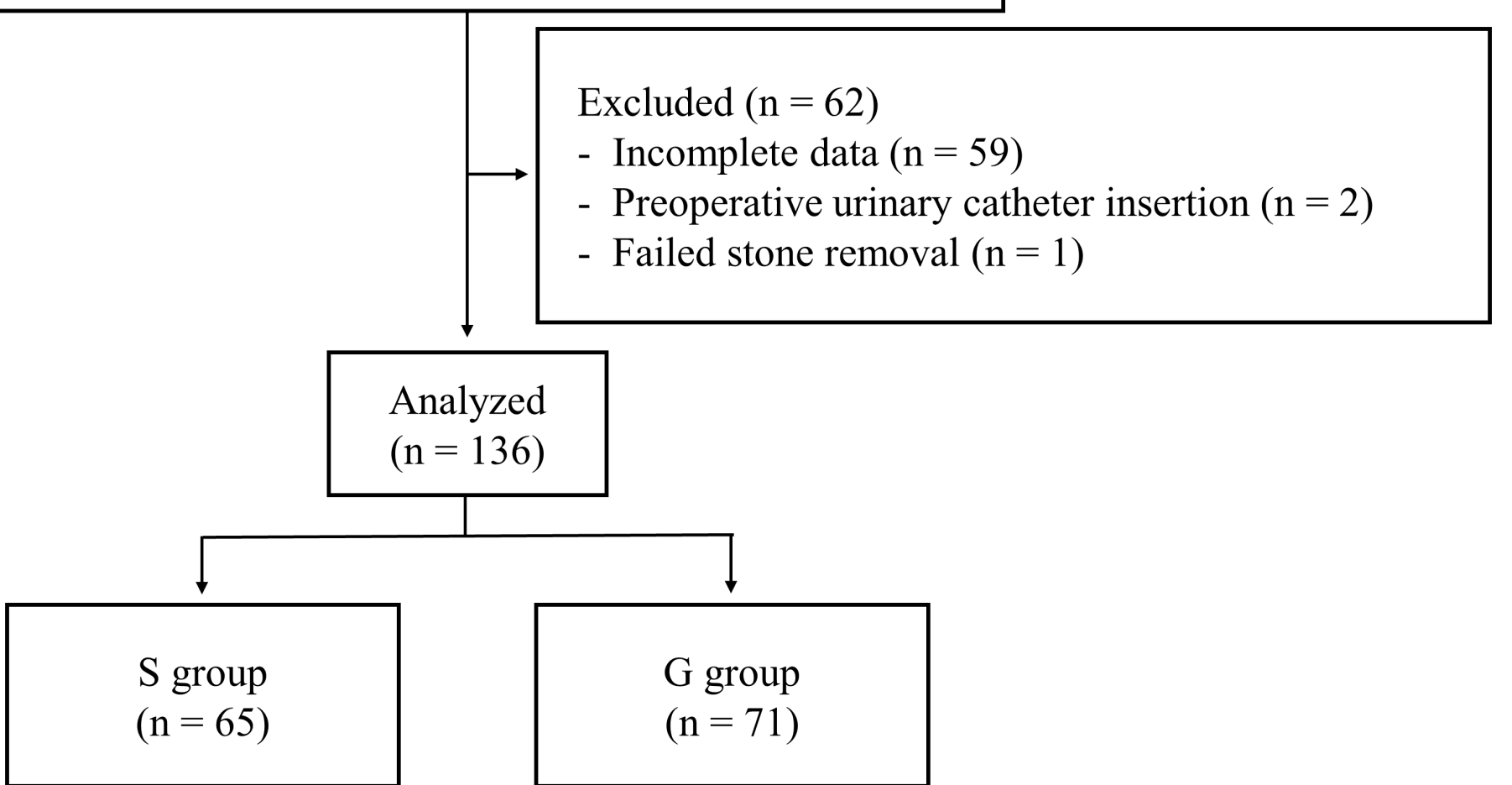

\section{Figure 1}

Flowchart showing the selection of study participants. The S group comprises patients who received sugammadex for the reversal of neuromuscular blockade. The $\mathrm{G}$ group comprises patients who received the glycopyrrolate-neostigmine mixture for the reversal of neuromuscular blockade. 


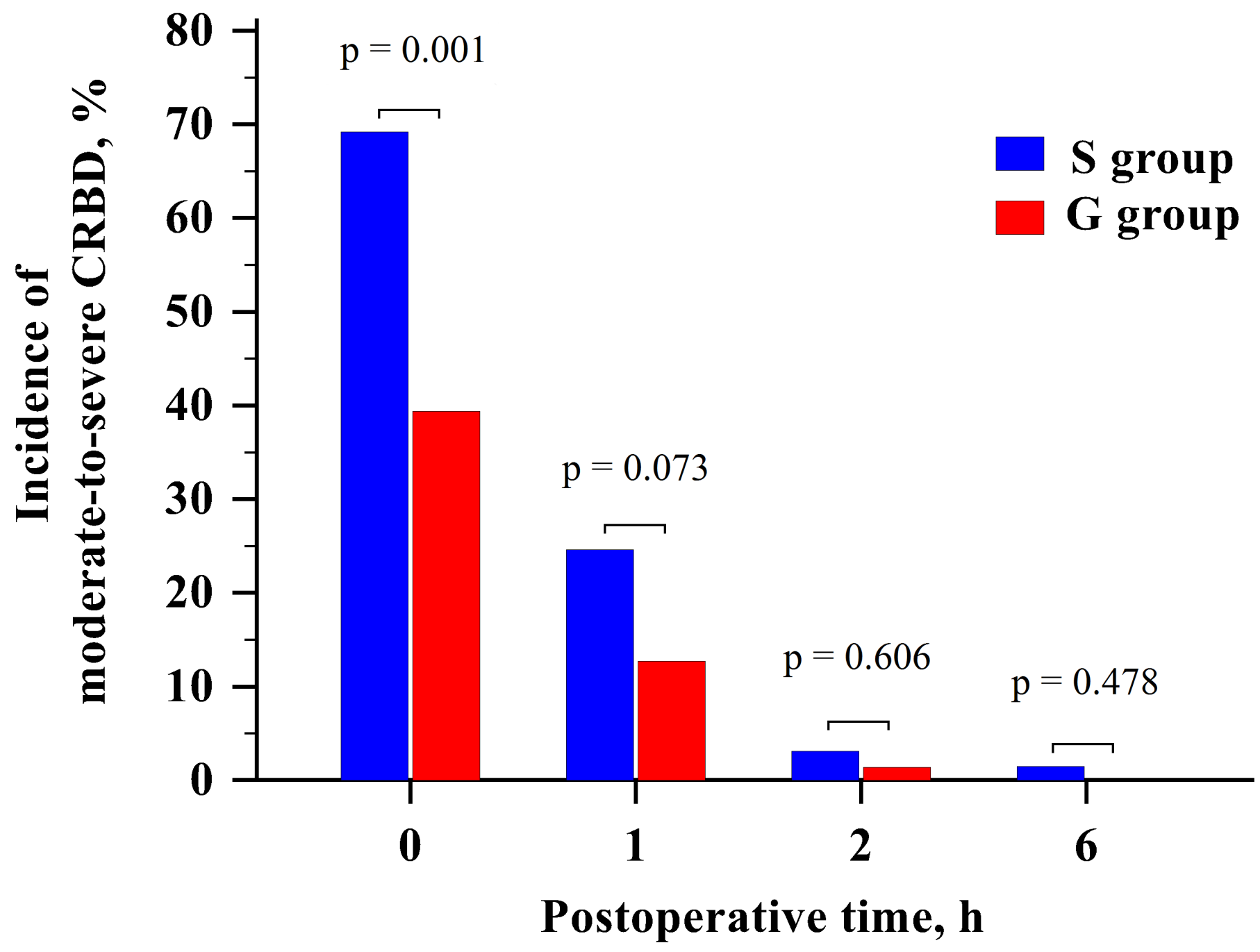

Figure 2

Comparison of the incidences of moderate-to-severe CRBD between the two groups at 0 (on admission to the postanesthetic care unit), 1, 2, and $6 \mathrm{~h}$ postoperatively. The $S$ group comprises patients who received sugammadex for the reversal of neuromuscular blockade. The $\mathrm{G}$ group comprises patients who received the glycopyrrolate-neostigmine mixture for the reversal of neuromuscular blockade. CRBD, catheter-related bladder discomfort. Data are analyzed using the $\chi 2$ test or Fisher's exact test. 


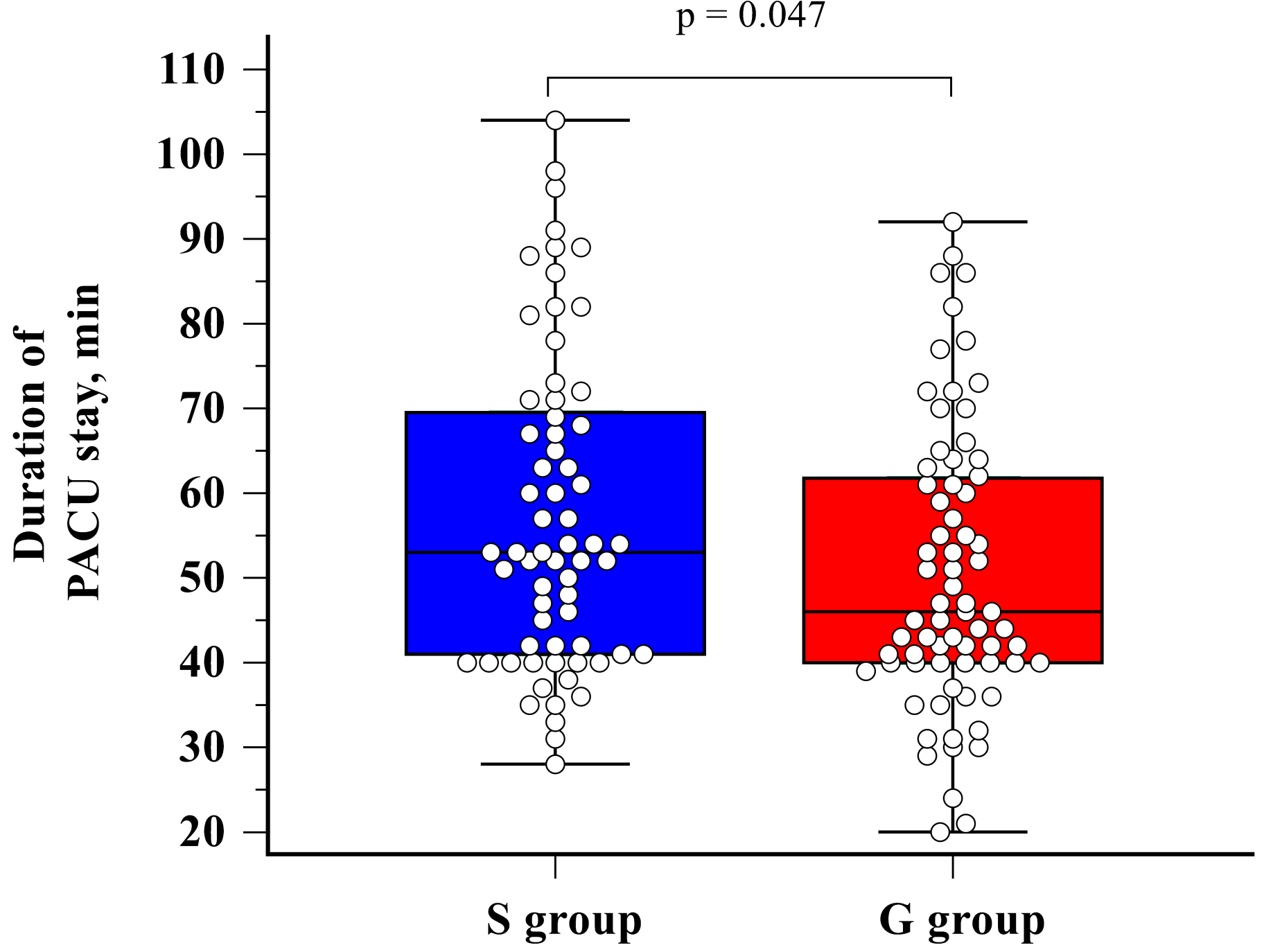

Figure 3

Comparison of the duration of PACU stay between the $\mathrm{S}$ group and $\mathrm{G}$ group. The $\mathrm{S}$ group comprises patients who received sugammadex for the reversal of neuromuscular blockade. The G group comprises patients who received the glycopyrrolate-neostigmine mixture for the reversal of neuromuscular blockade. PACU, postanesthetic care unit. The horizontal line in the rectangle shows the median values. The upper and lower lines of the box indicate the third quartile and first quartile, respectively. The whiskers above and below the box represent the maximum and minimum values, respectively. The scattered dots indicate the raw data. Data are analyzed using the Mann-Whitney $U$ test. 